\title{
Improving a Family's Overall Quality of \\ Life Through Parent Training in Pivotal Response Treatment
}

\author{
Trevor W. Buckley, MA 23 , Angela P. Ente, \\ $\mathbf{M A}^{2,3}$ \\ and Michael B. Ruef, PhD**34
}

\begin{abstract}
As the diagnoses of autism in young children continually increase, the need for families to have access to research-based treatment models that are effective and efficient has become clear. Current research demonstrates the demand for parent-delivered behavioral interventions. The aim of this single-case study, conducted as part of an integrated Masters in Education/Special Education Credential Program, was to examine the relationship between one parent trained in pivotal response treatment (PRT), her implementation of PRT techniques, and the correlated gains of behavioral compliance in her 6-year-old boy with high-functioning autism (HFA). Visual analysis of collected data as well as calculation of nonoverlapping data points suggest that a parent, when effectively trained, can utilize PRT to increase the rate of behavioral compliance of his or her own children.
\end{abstract}

Keywords

autism, PRT, quality of life, parent training

From our very first day working with the Ogden family it was clear that tantrums, rigidity, and other trademark characteristics of autism spectrum disorders (ASD) were having a daily, negative impact on this family's quality of life (QOL). Mr. and Mrs. Ogden were unsure of how to deal with problem behaviors of their young boy Jeremy, who has high-functioning autism (HFA). He was having a difficult time completing homework, complying with verbal requests, trying new foods, and the list goes on. We wanted to support this family not by simply creating a behavior plan for Jeremy but by giving Mr. and Mrs. Ogden useful, practical skills to manage difficult behavior. This was a goal that we felt would have a greater long-term impact on the entire family's overall QOL.

As graduate students pursuing master's degrees in special education, we were able to work closely with the Ogden family as part of an Autism Inquiry Project (AIP). This project required the implementation of an intervention that would seek to improve the family's QOL or provide support in whatever area the family felt was most needed. Although previous behavior-based interventions for Jeremy had resulted in some short-term gains, it was clear to us from the outset that the most beneficial intervention would be based on a parent-training model. Increasing the level of Jeremy's behavioral compliance was certainly one of our objectives, but our main goal was to help Mr. and Mrs. Ogden feel more confident in their ability to manage Jeremy's maladaptive behaviors.

\section{Impact on the Ogden Family's QOL}

The concept of QOL as it applies to families with children with disabilities is meant to address the levels of stress, satisfaction, and functionality within those families. As treatment models based on the principles of applied behavioral analysis (ABA) continue to develop, the social implications of autism and its effects on individual and family QOL have become important concerns for clinicians and practitioners (Billstedt, Gillberg, \& Gillberg, 2011; Garcia-Villamisar \& Dattilo, 2010; Khanna et al., 2011; Kuhlthau et al., 2010; Whitney, 2012). Recent studies point to a reduced level of QOL for families with children with ASD (Johnson, Frenn,

'Realizing Children's Strengths (RCS) Behavioral Consulting, Boston, MA, USA

${ }^{2}$ Koegel Autism Consultants, Santa Barbara, California, USA

${ }^{3}$ University of California, Santa Barbara, USA

${ }^{4}$ California Polytechnic State University, San Luis Obispo, USA

Corresponding Author:

Angela P. Ente, 994 Pellham Dr Lompoc CA 93436, USA.

Email: angelaente@yahoo.com 
Feetham, \& Simpson, 2011; Moyson \& Roeyers, 2011). As Mrs. Ogden noted regarding Jeremy’s noncompliance,

Sometimes going into new places or situations causes anxiety for the whole family, as we are never certain if he [Jeremy] will comply with our requests (whatever they may be), or become defiant and disrespectful.

From the very first day of our AIP, Mrs. Ogden expressed to us the numerous concerns she had regarding her son's behavior. His outbursts, meltdowns, and occasionally violent reactions placed a tremendous amount of stress on the entire family. One issue that was particularly stressful for Mrs. Ogden was Jeremy's rigidity when it came to food choice. He would only eat a few different foods, and this meant that wherever the Ogdens went to eat, Mrs. Ogden would have to bring one of those foods for Jeremy. Another issue, fear of public restrooms, kept the Ogdens from traveling to unfamiliar places or enjoying novel experiences such as going to birthday parties or community events. These and many other factors contributed to a reduced level of QOL for the Ogdens.

\section{Parent Training in Pivotal Response Treatment (PRT)}

Numerous researchers have documented the effectiveness of evidence-based parent-training treatment models (Ingersoll \& Dvortcsak, 2006; Koegel, Bimbela, \& Schreibman, 1996; Koegel \& Koegel, 2006; Lifter, 2008; Rocha, Schreibman, \& Stahmer, 2007; Singh et al., 2006), especially as it pertains to behavioral interventions for children with autism (Koegel, Koegel, \& Carter, 1999). Our plan for Mr. and Mrs. Ogden included (a) providing instructional PRT reading material, (b) showing video examples of PRT-based interventions as well as showing Mrs. Ogden videos of her own interactions with her son, (c) discussing the reading and videos, and (d) using role-playing scenarios to help the Ogdens get a more concrete understanding of how to implement PRT effectively.

\section{Training and Format}

Training was administered in the family's home. Mrs. Ogden agreed to the parent-training program to increase Jeremy's behavioral compliance. The level of Jeremy's behavioral compliance, which was termed the rate of compliance (ROC), was the dependent variable that was tracked during the study. To calculate the ROC, we divided the number of Jeremy's appropriate responses by the number of requests made by Mrs. Ogden. By making Mrs. Ogden's requests more effective through her implementation of PRT, we hoped to see an increase in the percentage of the ROC over the course of the intervention.
A request included any demand made of Jeremy that required a response and was within his repertoire. Requests included (a) Mrs. Ogden asking for Jeremy to complete a task, (b) Mrs. Ogden requesting help from Jeremy, or (c) Mrs. Ogden asking Jeremy to stop a particular behavior.

As part of the parent-training portion of our intervention, we showed Mrs. Ogden the difference between an appropriate and an inappropriate request through video modeling and role-playing scenarios. An appropriate request involved Mrs. Ogden obtaining Jeremy's attention before placing a demand on him. If Mrs. Ogden made a request of Jeremy without first gaining his attention, she was instructed to increase the level of prompting by tapping him on the arm and obtaining eye contact before redelivering her request. Mrs. Ogden was also taught how to utilize the PRT technique of providing choices when Jeremy was being noncompliant. The PRT Pocket Guide (2012) describes providing choices as using "child-preferred or child-selected materials, topics, and toys, and follow[ing] the child's lead during interactions" (Koegel \& Koegel, 2012, p. 44). For example, a child who struggles to put on his shoes before playing outside would be asked, "Do you want to put on your blue shoes or your red shoes?" Both choices result in the desired outcome. This strategy is meant to increase motivation by including the child in the decision-making process. Ideally, the choice that is used is related to the task; thus, the child receives natural reinforcement tied directly to his or her response (Koegel \& Koegel, 2012).

After having gathered sufficient baseline data, we began the training phase of our intervention, which involved explicit instruction in the principles and practices of PRT based on the PRT Pocket Guide. This part of the training was discussion-based and was covered in the first two training sessions. Some of the components we focused on from the PRT model included teaching the parents to (a) allow the child to choose which materials or activities to be used, (b) intersperse maintenance tasks with new acquisition tasks, and (c) provide choices (Koegel \& Koegel, 2012).

\section{Results and Interobserver Agreement (IOA)}

After 3 weeks of gathering baseline data, we found that Jeremy's average ROC was 50.2\%. Jeremy's baseline ROC indicated that when Mrs. Ogden made a request of Jeremy, he responded appropriately about half the time. During the 4 weeks that we administered our parent-training intervention, Jeremy's ROC increased from a baseline average of $50.2 \%$ to a mid-post-intervention average of $85 \%$. This represents a $70 \%$ increase in the overall ROC.

Figure 1 shows the percentage of Jeremy's appropriate responses during the baseline and mid-post-intervention 


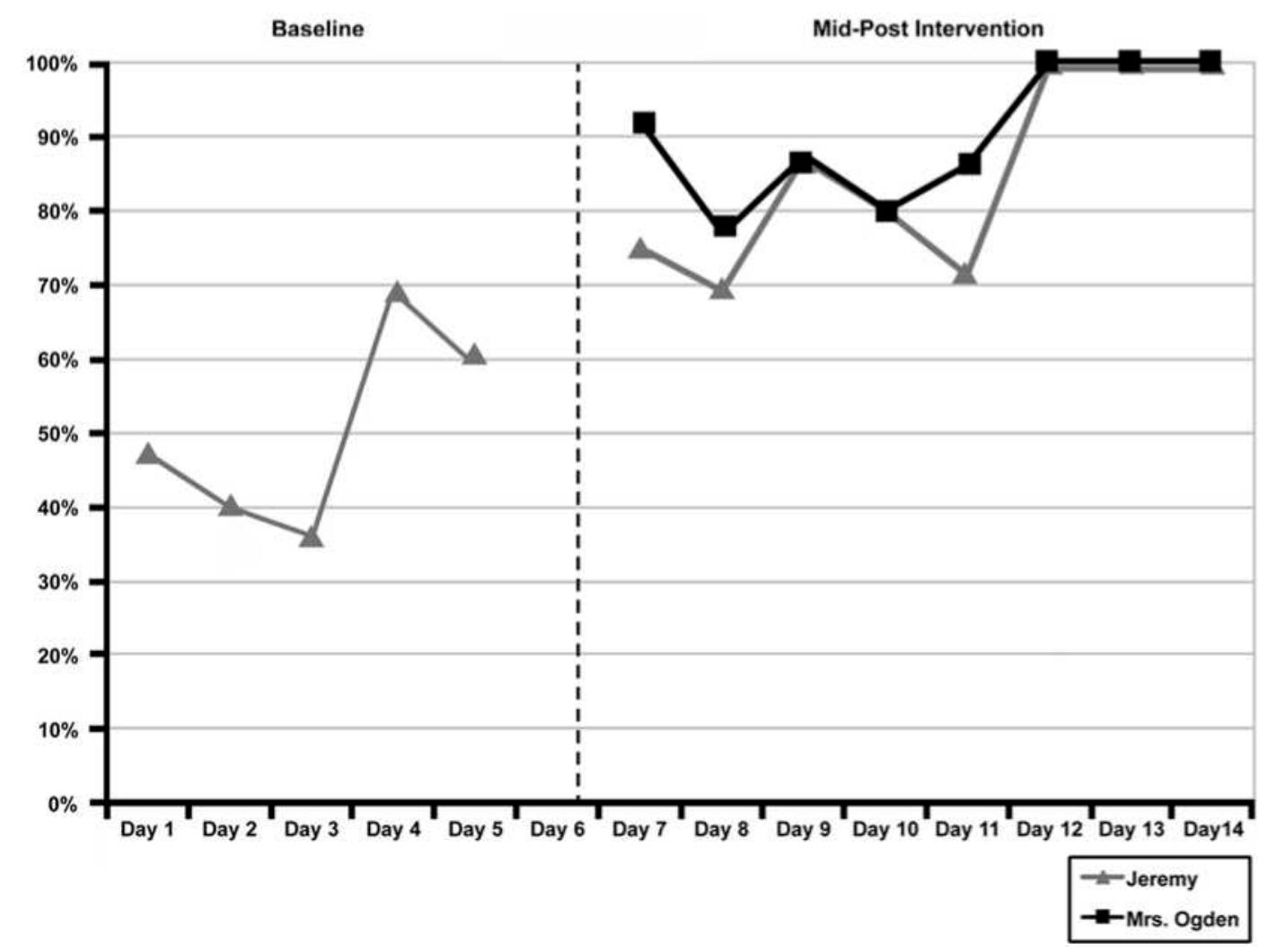

Figure 1. Percentage of Jeremy's appropriate responses at baseline and mid-post-intervention.

phases. It also provides the percentage of Mrs. Ogden's appropriate requests per session during the mid-post-intervention phase. In this figure, there is a clear correspondence between the instances in which Mrs. Ogden made an appropriate request and the instances in which Jeremy responded appropriately. As the percentage of Mrs. Ogden's appropriate requests increased, so did the percentage of Jeremy's appropriate responses.

Because individual family perceptions are an important measure of QOL, we have included quotes from Mrs. Ogden about the impact of our intervention:

Working with Trevor and Angela has improved the quality of our family life in a number of ways. First, they provided concrete examples of successful PRT interventions and then walked us through how we could apply them in our home.

We are profoundly grateful to have worked with Angela and Trevor and are truly sorry that our program has come to an end. But we are well aware that the benefits of this program will continue for years to come.

We have already seen the benefits from this training-our house is no longer an ever-escalating battle zone whenever we try to communicate with our son.
Our IOAs for Mrs. Ogden and Jeremy were 93\% and $91 \%$, respectively. Our percentage of nonoverlapping data (PND) points was 86\%, indicating an effective treatment. For this particular family, our intervention helped to increase the ROC in Jeremy and allowed Mr. and Mrs. Ogden to improve their ability to manage Jeremy's inappropriate behaviors.

\section{Collaboration Between Clinicians and Parents}

For this study, the most important component was the parent-clinician collaboration, because parents who are trained to deliver an ABA-based behavioral intervention (Cooper, Heron, \& Heward, 2007) have higher rates of satisfaction and lowered stress levels (Dillenburger, Keenan, Gallagher, \& McElhinney, 2004). Giving parents feedback about the way they interact with their children can be a dangerous proposition, in part because parents can feel as though they are being judged on the quality of their parenting skills. When providing feedback for the Ogdens, we based our strategy on offering positive support, complimenting successes, building on what they already knew, and using firstperson examples to highlight criticisms. If, for example, 
Mrs. Ogden gave an instruction but did not provide a consistent consequence, we would say, "I liked the way you gave a clear instruction. When I work with a kiddo, I find it important to give a clear instruction and follow through with the appropriate consequence."

Because we were working in a family's home, we wanted our intervention to appear natural so that both the parents and the children were comfortable with transition. PRT is based on the principles of ABA and seeks to improve a child's impairments through environmental manipulations and "naturally occurring teaching opportunities" (BakerEriczen, Stahmer, \& Burns, 2007, pp. 52-53). We found PRT suitable because it has been used extensively to train parents, and its effectiveness has been well documented.

\section{Discussion}

If future studies were to be conducted, a larger participant pool and long-term assessment tools would help researchers to know whether the intervention was successful across families and whether skills taught to parents remained a part of their repertoire. For this study, no long-term assessments were conducted, so the clinicians were unable to track whether the family's increased QOL was sustained, increased, or diminished over time. Follow-up meetings, observations, and trainings might help to maintain longterm improvement in parent behavior.

The concept of QOL within a family is somewhat abstract. A key component includes the overall satisfaction of the family, which is largely based on the perceptions of individuals within that family. Although it is important to help kids with ASD increase appropriate behaviors, it can be equally important for parents to feel that they are (a) in control and (b) doing the right thing. In the case of the Ogden family, it was our hope that Jeremy would increase his appropriate behaviors, but it was also our goal to help Mr. and Mrs. Ogden feel more successful and satisfied as parents.

\section{Declaration of Conflicting Interests}

The author(s) declared no potential conflicts of interest with respect to the research, authorship, and/or publication of this article.

\section{Funding}

The author(s) received no financial support for the research, authorship, and/or publication of this article.

\section{References}

Baker-Ericzen, M., Stahmer, A., \& Burns, A. (2007). Child demographics associated with outcomes in a community-based pivotal response training program. Journal of Positive Behavior Interventions, 9, 52-60.

Billstedt, E., Gillberg, I., \& Gillberg, C. (2011). Aspects of quality of life in adults diagnosed with autism in childhood: A population-based study. Autism: The International Journal of Research and Practice, 1, 5, 7-20.
Cooper, J. O., Heron, T. E., \& Heward, W. L. (2007). Applied behavior analysis (2nd ed.). Upper Saddle River, NJ: Prentice Hall.

Dillenburger, K., Keenan, M., Gallagher, S., \& McElhinney, M. (2004). Parent education and home-based behavior analytic intervention: An examination of parents' perceptions of outcome. Journal of Intellectual \& Developmental Disability, 29, 119-130.

Garcia-Villamisar, D. A., \& Dattilo, J. J. (2010). Effects of a leisure programme on quality of life and stress of individuals with ASD. Journal of Intellectual Disability Research, 54, 611-619. doi: 10.1111/j.1365-2788.2010.01289.x

Ingersoll, B., \& Dvortcsak, A. (2006). Including parent training in the early childhood special education curriculum for children with autism spectrum disorders. Topics in Early Childhood Special Education, 26, 179-187.

Johnson, N., Frenn, M., Feetham, S., \& Simpson, P. (2011). Autism spectrum disorder: Parenting stress, family functioning and health-related quality of life. Families, Systems, \& Health, 29, 232-252. doi:10.1037/a0025341

Khanna, R., Madhavan, S., Smith, M. J., Patrick, J. H., Tworek, C., \& Becker-Cottrill, B. (2011). Assessment of healthrelated quality of life among primary caregivers of children with autism spectrum disorders. Journal of Autism and DevelopmentalDisorders, 41, 1214-1227.

Koegel, R. L., Bimbela, A., \& Schreibman, L. (1996). Collateral effects of parent training on family interactions. Journal of Autism and Developmental Disorders, 26, 347-359.

Koegel, R. L., \& Koegel, L. K. (2006). Pivotal response treatments for autism: Communication, social, \& academic development. Baltimore, MD: Paul H. Brookes.

Koegel, R. L., \& Koegel, L. K. (2012). PRT pocket guide: Pivotal response treatment for autism spectrum disorders. Baltimore, MD: Paul H. Brookes.

Koegel, R. L., Koegel, L. K., \& Carter, C. M. (1999). Pivotal teaching interactions for children with autism. School Psychology Review, 28, 576.

Kuhlthau, K., Orlich, F., Hall, T., Sikora, D., Kovacs, E., Delahaye, J., \& Clemons, T. (2010). Health-related quality of life in children with autism spectrum disorders: Results from the autism treatment network. Journal of Autism and Developmental Disorders, 40, 721-729. doi:10.1007/s10803-009-0921-2

Lifter, K. (2008). Teaching reciprocal imitation skills to parents of young children with autism supports socially valid parent engagement with their children. Evidence-Based Communication Assessment and Intervention, 2, 14-16. doi:10.1080/17489530801948688

Moyson, T., \& Roeyers, H. (2011). The quality of life of siblings of children with autism spectrum disorder. Exceptional Children, 78, 41-55.

Rocha, M. L., Schreibman, L. L., \& Stahmer, A. C. (2007). Effectiveness of training parents to teach joint attention in children with autism. Journal of Early Intervention, 29, 154-173.

Singh, N. N., Lancioni, G. E., Winton, A. W., Fisher, B. C., Wahler, R. G., McAleavey, K., \& Sabaawi, M. (2006). Mindful parenting decreases aggression, noncompliance, and self-injury in children with autism. Journal of Emotional and Behavioral Disorders, 14, 169-177.

Whitney, R. (2012). Autism and family quality of life. OT Practice, 17, 10-14. 